\title{
Synthesis and curing process of TMA-MDI polyamide-imides
}

\author{
Yuhong Qiं , Bingnan Ji, Li Li and Zhanping Zhang \\ Department of Materials Science and Engineering, Dalian Maritime University, Dalian 116026, China
}

\begin{abstract}
The influence of molecular ratio of monomers, reaction time, reaction temperature and solid content on the molecular weight of polyamide imides(PAI), heating rate, temperature and time on tensile properties of PAI film was investigated in detail. The results showed that when monomer molar ratio (MDI: TMA)R $>1$, PAI is an isocyanate terminated, intrinsic viscosity increases with the increase of $\mathrm{R}$, reaches maximum value at $\mathrm{R}=1.06$, then it decreases obviously. Contrarily, when $\mathrm{R}<1, \mathrm{PAI}$ is terminated with anhydride, intrinsic viscosity increases with the decrease of $\mathrm{R}$, its maximum value at $\mathrm{R}=0.97$, then it decreases with the decrease of $\mathrm{R}$. The relation between intrinsic viscosityof PAI and reaction temperature, reaction time, solid content all follows the parabolic law. The optimal reaction temperature, reaction time, solid content is $140^{\circ} \mathrm{C}, 120 \mathrm{~min}, 30 \%$. Therefore, the best synthesis process of the PAI is reacting for $120 \mathrm{~min}$ at $140^{\circ} \mathrm{C}$ when $30 \%$ solid content and $\mathrm{R}=1.06$. Tensile strength and elongation increase with the increase of heating rate, curing temperature and curing time, after peak value, they decrease with the increase of heating rate, curing temperature andcuring time. The best curing process of the PAI is curing for $2 \mathrm{~h}$ at $260^{\circ} \mathrm{C}$ and heating rate $100^{\circ} \mathrm{C} / \mathrm{h}$.
\end{abstract}

\section{Background}

Polyamide-imide (PAI) is a kind of high-performance thermoplastic resin.It isused for advanced applications, such as in the electrical, aerospace, automobile and energy fields in the form of adhesives, composite materials and coating materials, related to their combinationof high toughness, high thermal stability, high glass transition temperature and enhanced chemical resistance[1-5]. Polyamide-imide can be obtained from different strategies of synthesis. Commonly used synthesis routes are the acid chloride and the diisocyanate route. At the acid chloride route reaction between trimellitic acid chloride and an aromatic diamine yields in formation of a poly(amideamic acid). The formation of imide structures is obtained either due to dehydration of the acid intermediate, addition of tertiary amines or anhydrides [6-8]. But this route is long process flow and the storage stability of the product is poor. The diisocyanate route is based on the work of Hitachi Chemical Corp. [9] and today most common for preparation of PAI resins. Thisroute is simple, but the subsequent high temperature curing affects the properties of the material. Additionally obtained PAI product is very easy to cracking. The PAI structure obtained by diisocyanate route has been characterized extensively by NMR techniques [10-12]. Statistical distributions of imide-imide, amide-imide, and amide-amide linkages were observed [13]. In fact, the properties of PAI not only depend on its synthesis, but also curing process [14]. However there are little reports and publications about synthesis and curing process. It limits the application and development of PAI. Therefore, this work investigated indetail the influence of molecular ratio of monomers, reaction time, reaction temperature and solid content on the molecular weight of PAI resin; heating rate, curing temperature and curing time on tensile properties of PAIfilm, to understand and determine the best synthesis and curing process of PAI.

\section{Experimental}

\subsection{Materials}

1,2,4-Benzenetricarboxylic anhydride (TMA), 4,4'Diphenylmethane Diisocyanate(MDI) and N-NDiommethylacetamide (DMAc) were purchased from Aladdin. DMAc was dewatered over 4A molecular sieve before use. TMA and MDI were used as received.

\subsection{Synthesis of PAlresin}

The PAI from 1,2,4-Benzenetricarboxylic anhydride (TMA) and 4,4'-Diphenylmethane Diisocyanate(MDI) in N-N-Dimethylacetamide (DMAc) were synthesized in a four-neck, round bottom, Pyrex reaction flask equipped with a mechanical stirrer, reflux condenser, addition funnel and nitrogen inlet. Its reaction scheme is shown in Figure 1.

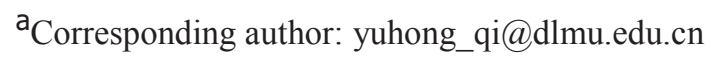




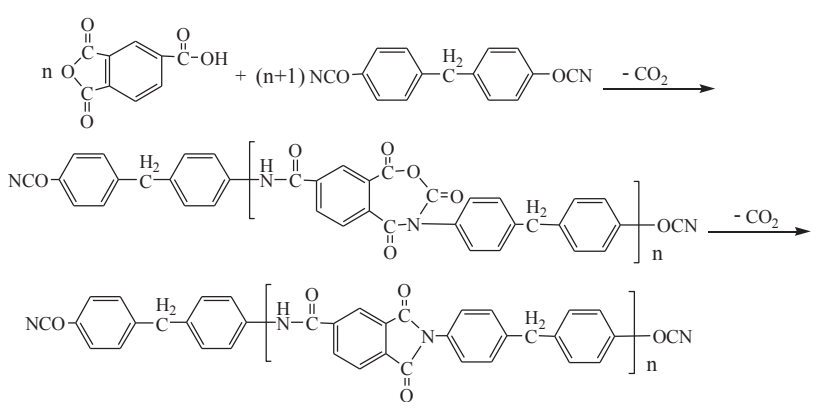

Figure 1. Reaction scheme of PAI

\subsection{Curing of PAl}

The curing test was carriedout in high temperature furnace. The curing samples were prepared by coating PAI resin on glass slide.

\subsection{Characterizations}

The molecular weight of PAI before curing were characterized with intrinsic viscosity $\eta_{\mathrm{r}}$ which tested with Ubbelohde Viscometer for $0.5 \mathrm{~g} / \mathrm{dL}$ at $30^{\circ} \mathrm{C}$.

Mechanical properties of PAI film were characterized with strength and elongation from tensile test which were carried out on XLW Tensile Tester (Labthink Instruments Co., Ltd) equipped with a $500 \mathrm{~N}$ load cell at a constant strain rate $50 \mathrm{~mm} / \mathrm{min}$ for film dimensions of $4 \mathrm{~mm}$ width and $60 \mathrm{~mm}$ length and the gauge length was set as $20 \mathrm{~mm}$. Three samples for each formulation were measured for statistical accuracy.

\section{Results and Discussion}

\subsection{Synthesis}

In the different stages of PAI synthesis, the intrinsic viscosity of the reaction products will change obviously with the reaction condition. Therefore, it is possible to evaluate the synthesis process of PAI by measuring the intrinsic viscosity of the product.

The results showed that the intrinsic viscosity $\left(\eta_{\mathrm{r}}\right)$ of PAI resin is closely related to reaction temperature, reaction time, solid content and monomer molar ratio (MDI: TMA) R. As shown in Figure 2, once the reaction temperature reached $120{ }^{\circ} \mathrm{C}, \eta_{\mathrm{r}}$ began to increase significantly, and it increases with temperature; but once the temperature more than $140^{\circ} \mathrm{C}$, the solution tends to be black and brown, it may be associated with oxidative crosslinking.

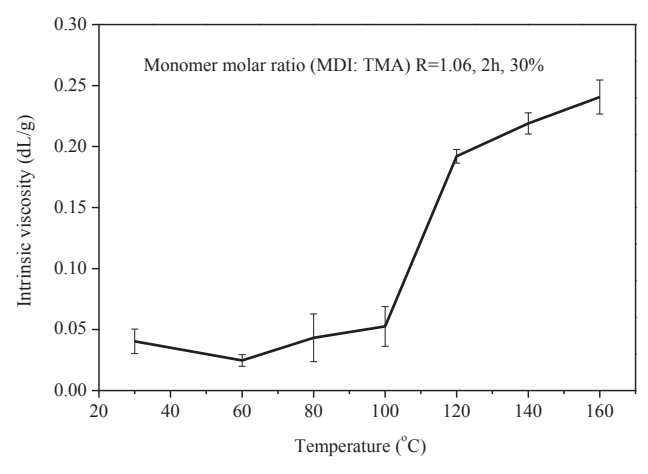

Figure 2. Variation of intrinsic viscosity of PAI with reaction temperature.

The reaction time is within $120 \mathrm{~min}, \eta_{\mathrm{r}}$ increased with time, as shown in Figure 3, after 120 min, $\eta_{\mathrm{r}}$ decreases with time increase; $\eta_{\mathrm{r}}$ increases with solid content, as shown in Figure 4, it reaches the maximum value at solid content is $30 \%$, then $\eta_{\mathrm{r}}$ decreases with increasing solid content.

As shown in Figure 5, when monomer molar ratio (MDI: TMA)R $>1$, PAI is an isocyanate terminated, $\eta_{\mathrm{r}}$ increases with the increase of $\mathrm{R}, \eta_{\mathrm{r}}$ reaches maximum value at $R=1.06$, then $\eta_{\mathrm{r}}$ decreases obviously with the increase of R. Contrarily, when $\mathrm{R}<1$, PAI is terminated with anhydride, $\eta_{\mathrm{r}}$ increases with the decrease of $\mathrm{R}$, the maximum value of $\eta_{r}$ at $R=0.97$, then it decreases with the decrease of $\mathrm{R}$. Therefore, the best synthesis process of the PAI is reacting for $120 \mathrm{~min}$ at $140{ }^{\circ} \mathrm{C}$ when $30 \%$ solid content and $\mathrm{R}=1.06$.

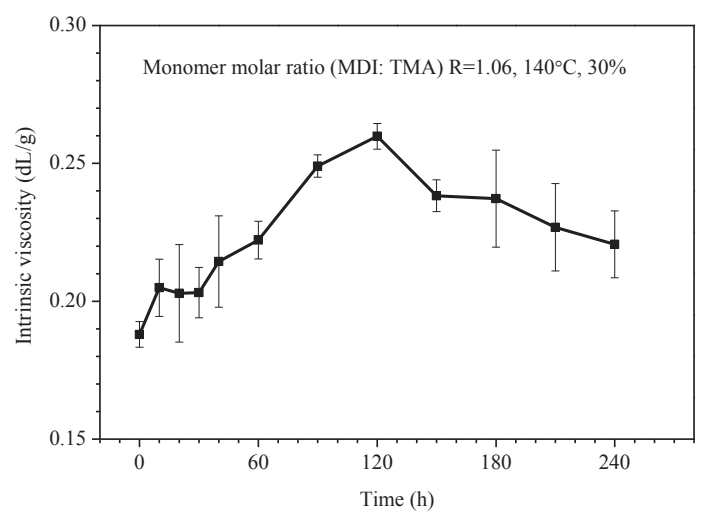

Figure 3. Variation of intrinsic viscosity of PAI with reaction time. 


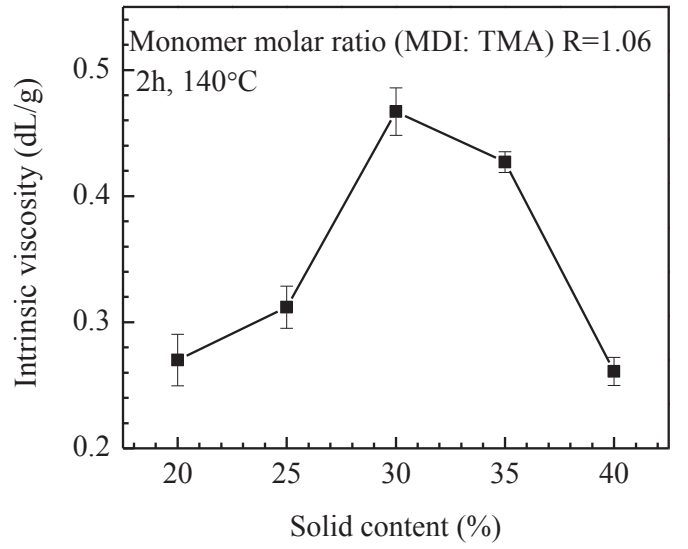

Figure 4. Variation of intrinsic viscosity of PAI with solid content.

\subsection{Curing}

The curing process parameters, such as heating rate, curing temperature and curing time, have important influence on the tensile properties of PAI film. The influence of curing parameters on the tensile strength and elongation is almost the same. As shown in Figure 6, Figure 7 and Figure 8, the results showed that tensile strength and elongation increase with the increase of heating rate, curing temperature and curing time, after peak value, they decrease with the increase of heating rate, curing temperature and curing time. For the TMA-MDI polyamide-imidesstudiedin this paper, proposed bestcuring process of the PAI is curing for $2 \mathrm{~h}$ at $260^{\circ} \mathrm{C}$ and heating rate $100{ }^{\circ} \mathrm{C} / \mathrm{h}$. Using this proposed best curing process, the highest tensile strength and elongation is respectively up to $117.03 \mathrm{MPa}$ and $14.18 \%$. PAI cured has good mechanical properties.

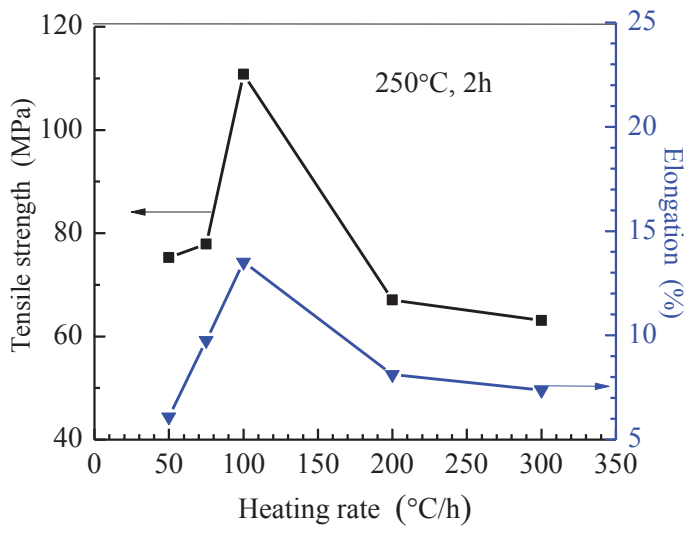

Figure 6. Variation of tensile strength and elongation of PAI films with heating rate.

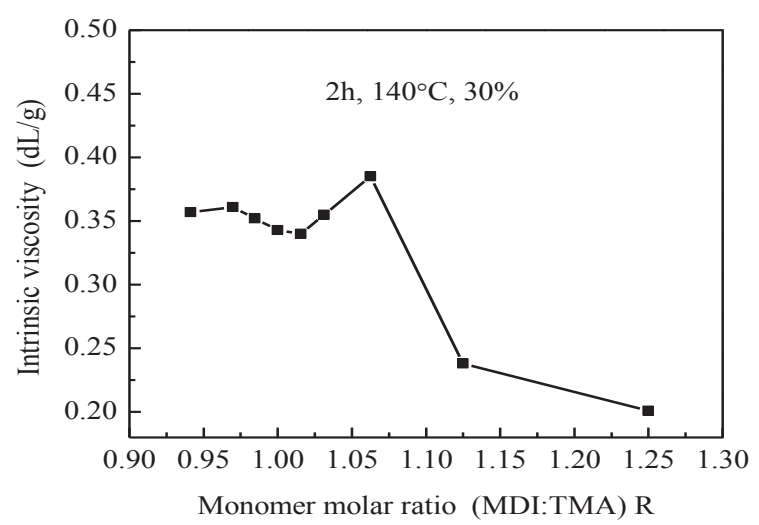

Figure 5. Variation of intrinsic viscosity of PAI with monomer molar ratio.

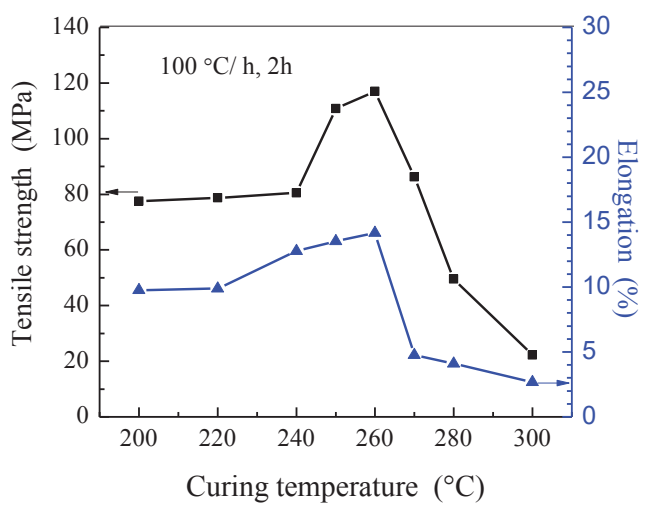

Figure 7. Variation of tensile strength and elongation of PAI films with curing temperature.

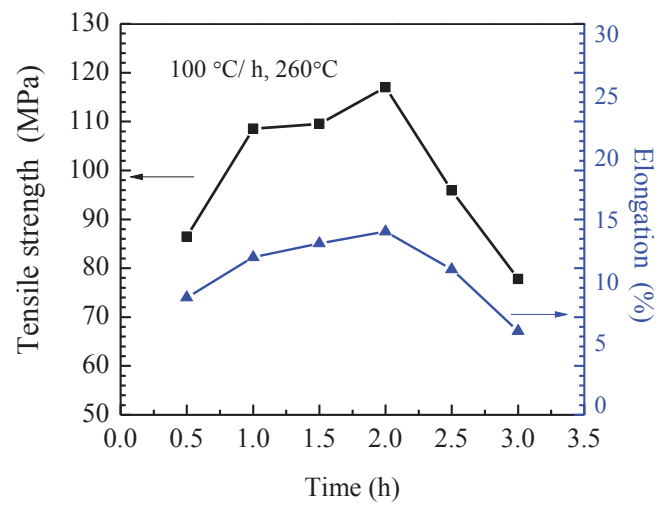

Figure 8. Variation of tensile strength and elongation of PAI films with curing time.

\section{Conclusions}

When monomer molar ratio (MDI: TMA) $\mathrm{R}>1$, PAI is an isocyanate terminated, intrinsic viscosity increases with the increase of $\mathrm{R}$, reaches maximum value at $\mathrm{R}=1.06$, then it decreases obviously. Contrarily, when $\mathrm{R}<1$, PAI is terminated with anhydride, intrinsic viscosity increases 
with the decrease of $\mathrm{R}$, its maximum value at $\mathrm{R}=0.97$, then it decreases with the decrease of $\mathrm{R}$. The relation between intrinsic viscosity of PAI and reaction temperature, reaction time, solid content all follows the parabolic law. The optimal reaction temperature, reaction time, solid content is $140{ }^{\circ} \mathrm{C}, 120 \mathrm{~min}, 30 \%$. Therefore, the best synthesis process of the PAI is reacting for $120 \mathrm{~min}$ at $140^{\circ} \mathrm{C}$ when $30 \%$ solid content and $\mathrm{R}=1.06$. Tensile strength and elongation increase with the increase of heating rate, curing temperature and curing time, after peak value, they decrease with the increase of heating rate, curing temperature and curing time. The best curing process of the PAI is curing for $2 \mathrm{~h}$ at $260^{\circ} \mathrm{C}$ and heating rate $100^{\circ} \mathrm{C}$ $/ \mathrm{h}$.

\section{Acknowledgments}

This work was supported by National nature science foundation of China (51179011), defense fund. The authors gratefully acknowledge for financial support.

\section{References}

1. M. Barikani, S. M. Ataei, J. Polym. Sci. A: Polym. Chem. 37, 2245(1999)

2. X. Ma, N.-H. Lee, H.-J. Oh, J.-S. Hwang, S.-J. Kim, Nanoscale Res. Lett. 5, 1846 (2010)

3. D. Liaw, W. Chen, Polym. Degrad. Stab. 91, 1731(2006)

4. M. Son, Y. Ha, M. C. Choi, T. Lee, D. Han, S. Han, C.S. Ha, Eur. Polym. J. 44, 2236(2008)

5. Z. Nie, A. Petukhova, E. Kumacheva, Nat. Nanotechnol. 5, 15(2010)

6. T. J. Murray, Macromol. Mater. Eng. 293, 350-360 (2008)

7. Nemours P De, United States Patent 3179360 (1965)

8. A. L. Endrey, V. Nostnand, United States Patent 3179631 (1962)

9. A. L. Endrey, United States Patent 3179633 (1965)

10. J. Campa, la. de, Die Makromol. Chem. 578, 571578(1982)

11. J. Nieto, Die Makromol. Chem. 569, 557-569(1982)

12. N. Sintès-Zydowicz, Die Makromol. Chem. 2307, 2295-2307(1993)

13. D. Briesenick, W. Bremser, Progress in Organic Coatings, 82, 26-32 (2015)

14. L. Li, Y. Qi. Polymer Mater. Sci. \& Eng. 31, 79(20 